Año 10.

Frontera

Núm. 26
Revista de Investigación

Académica sin

ISSN: 2007-8870

http://revistainvestigacionacademicasinfrontera.com

\title{
Fundamentos de la normatividad empresarial para el desarrollo económico y social en una sociedad en trasformación.
}

Dra. María Guadalupe Almada Quintero'; Lic. Armando Medina Wahnnatah ${ }^{2}$

\begin{abstract}
Resumen
Dentro del ámbito empresarial existen muchas formas de constituir y operar una empresa de forma individual o de forma asociada, si bien es cierto, todas las actividades y las conductas que se encuentran reguladas por el estado están sometidas a un régimen jurídico, de tal forma, que este régimen se encuentra establecido por la legislación vigente en función de la figura o el negocio de que se trate. Resulta para este análisis de gran importancia la normatividad legal vigente a considerar en cualquier organización o modalidad empresarial del sector productivo que desde un principio hace posible que le empresa formalmente funcione, vistos como un conjunto de preceptos que contribuyen a la creación de un ente o sujeto activo que es la organización y a través de sus actividades contribuir a las bases del crecimiento y desarrollo económico y social de la nación
\end{abstract}

Palabras clave: Normatividad empresarial, capital humano, desarrollo económico

\footnotetext{
${ }^{1}$ Doctora en Planeación y Liderazgo Educativo por la Universidad del Valle de México. Campus Hermosillo. Docente en la Universidad Estatal de Sonora, en la licenciatura en Administración de empresas, magaq@hotmail.com

${ }^{2}$ Licenciado en Derecho por la Universidad de Sonora. Docente en el Instituto Tecnológico de Sonora. Campus Navojoa. licarmandomedinaw@hotmail.com
} 
Año 10.

Frontera

Núm. 26
Revista de Investigación

Académica sin

ISSN: 2007-8870

\title{
http://revistainvestigacionacademicasinfrontera.com
}

\begin{abstract}
Within the business there are many ways to establish and operate a company individually or in partnership, if it is true, all the activities and behaviors that are regulated by the State are subject to a legal regime, in such a way, that this regime is established by the current legislation on the basis of the figure or the business concerned. It is for this analysis of great importance the applicable legal regulations in force to consider in any organization or business mode of the productive sector that from a principle makes it possible for the company to formally work, seen as a set of precepts which contribute to the creation of an entity or active subject is the organization and through their activities contribute to the growth and economic and social development of the nation.
\end{abstract}

Keywords: Business regulations, human capital, economic development

\section{Introducción}

La normatividad organizacional es un tema de gran alcance y que recobra vital importancia no sólo porque las empresas adoptan muy diversas formas en cuanto 
Año 10.

Frontera

Núm. 26
Revista de Investigación

Académica sin

ISSN: 2007-8870

http://revistainvestigacionacademicasinfrontera.com

a su tamaño, sector y dimensiones espaciales, sino también en lo que respecta a la forma en que se administran y dirigen, a su condición jurídica y a sus objetivos de operatividad.

Es indudable que las empresas forman parte de la sociedad, tienen una gran influencia en las comunidades con las que interactúan, por lo que es fundamental fortalecer las instituciones y los sistemas de gobierno en relación con la actividad

empresarial, procurando combinar de manera sólida y eficaz los recursos humanos, financieros y naturales.

Si bien es cierto, el entorno empresarial abarca diferentes elementos que tienen gran influencia en la empresa, en su formación y crecimiento, es importante que permita ampliar sus actividades, crear incentivos y estimular la formalización de la actividad empresarial, así como fomentar la inversión.

Vale la pena reflexionar en relación a los procedimientos para el registro y operatividad de las empresas, un sistema jurídico que impulse al crecimiento de las empresas, de ahí la importancia de profundizar en los aspectos relacionados con el entorno jurídico y su reglamentación destacando; el marco legislativo, el registro de empresas, las licencias, entre otros.

En cualquier escenario, existe la necesidad de recurrir a la normatividad por lo que es importante que esta sea interpretada y aplicada de una manera correcta para procurar la disminución de costos, aumentar la productividad y lograr un equilibrio y proporción entre las empresas y los ciudadanos, se trata de establecer una reglamentación adecuada, inteligente, eficaz y eficiente.

En este mismo sentido, es importante considerar que las empresas constantemente actúan en sistemas cada vez más complejos con mayores exigencias éticas, 
Año 10.

Frontera

Núm. 26
Revista de Investigación

Académica sin

ISSN: 2007-8870

\section{http://revistainvestigacionacademicasinfrontera.com}

sociales y normativas en su operatividad, lo cual promueve la constitución y mantenimiento de empresas sostenibles, con una visión al futuro, adoptando y aplicando la normatividad empresarial.

\section{Método}

En esta investigación se emplea un enfoque con elementos cualitativos, con base en el análisis de contenido y la interpretación de la información, se apoya en un diseño exploratorio para la obtención de información relacionada con una problemática o con el fenómeno a investigar (Hernández, Sampieri 2003). Se recopila y son parte de este análisis aspectos teóricos relevantes y diferentes estudios doctrinarios que sirven de apoyo como parte del estado del arte, para documentar los fundamentos generales del marco legal y regulatorio de las organizaciones, desde su establecimiento y operatividad, para mejorar el proceso de comprensión de la información y el análisis, para estar en posibilidades de conocer su aplicabilidad, impactos, beneficios y contribuciones del marco normativo vigente en el desarrollo y crecimiento de las organizaciones y por ende en él desarrollo económico y social del país.

\section{Resultados}

Partiendo con este análisis es importante retomar desde un inicio los preceptos de la Constitución Política de los Estados Unidos Mexicanos, misma que establece en el artículo 25 la responsabilidad del Estado en el desarrollo nacional, de forma integral y sustentable, mediante el fomento del crecimiento económico y el empleo y una más justa distribución del ingreso y la riqueza, permita el pleno ejercicio de la 
Año 10.

Frontera

Núm. 26
Revista de Investigación

Académica sin

ISSN: 2007-8870

\section{http://revistainvestigacionacademicasinfrontera.com}

libertad y la dignidad de los individuos, grupos y clases sociales. De igual manera, se contempla que el estado planeará, conducirá, coordinará y orientará la actividad económica nacional, y llevará al cabo la regulación y fomento de las actividades que demande el interés general en el marco de libertades consagradas por la Ley Máxima en la Federación; preceptuando adicionalmente que al desarrollo económico nacional concurrirán, con responsabilidad social, el sector público, el sector social y el sector privado, sin menoscabo de otras formas de actividad económica que contribuyan al desarrollo de la Nación. Destaca que en términos del precepto legal en cita, se apoyará e impulsará a las empresas de los sectores social y privado de la economía, sujetándolos a las modalidades que dicte el interés público y al uso, en beneficio general, de los recursos productivos, bajo criterios de equidad social y productividad; y que es prioridad, alentar y proteger la actividad económica que realicen los particulares; así como, proveer las condiciones para que el desenvolvimiento del sector privado contribuya al desarrollo económico nacional. (Cámara de diputados del H. Congreso de la Unión, 2017).

El marco legislativo vigente encargado de regular la actividad empresarial en definitiva debe contribuir al desarrollo de la colectividad, como un proceso con efectos positivos y de gran impacto en los aspectos económico, social, cultural y político, tendientes al mejoramiento del bienestar de toda la población y de todos los individuos sobre la base de una distribución justa de los beneficios que de él se derivan. En este sentido, el desarrollo de un país propicia las condiciones necesarias para que los estados sean capaces de responder a las demandas sociales y mejorar la calidad de vida de la ciudadanía. El aumento de las tasas de empleo, el alza del poder adquisitivo, la mayor capacidad recaudatoria y 
Año 10.

Frontera

Núm. 26
Revista de Investigación

Académica sin

ISSN: 2007-8870

\section{http://revistainvestigacionacademicasinfrontera.com}

redistributiva del estado mediante políticas públicas pertinentes, se traducen en beneficios tangibles para el grueso de la población, lo que facilita que los derechos humanos, específicamente los derechos económicos y sociales, sean una realidad y no solo postulados retóricos (Zaldívar, 2014).

La relación entre el conjunto de leyes y el desarrollo económico resulta de gran interés práctico y académico entre diversos actores nacionales e internacionales. El Banco Mundial (BM), el Fondo Monetario Internacional (FMI), el Programa de las Naciones Unidas para el Desarrollo (PNUD), junto con diversos gobiernos y organizaciones privadas del mundo desarrollado han resaltado la importancia de establecer un marco legal y judicial que haga posible el progreso económico a través de la acción del mercado, para lo cual resulta importante las iniciativas y acciones que transformen las condiciones socioeconómicas a través de las leyes, que garanticen el marco jurídico para el funcionamiento de la economía y los derechos de propiedad, encaminadas al logro de objetivos socioeconómicos tanto de la nación como de la sociedad en general (Burgos, 2002).

En este mismo sentido y retomando a Moreno (2010), refiere que los fundamentos legales de la organización empresarial cobra mayor realce y promoción a partir del auge de las PyME, esto se deriva de los principios y contenidos del derecho mercantil, estudia a la persona jurídica-colectiva. Su mérito es mostrar la estructura legal, en la cual puede constituirse una empresa, donde su organización, sus decisiones y actividades tengan sustento en la norma jurídica, que guíe la formulación de estatutos y reglas operativas de naturaleza mercantil, laboral, administrativa, fiscal y económica, condicionantes del control y la seguridad interna. 
Año 10.

Frontera

Núm. 26
Revista de Investigación

Académica sin

ISSN: 2007-8870

\section{http://revistainvestigacionacademicasinfrontera.com}

Por otra parte, de acuerdo con Corona (2012), las principales disciplinas que inciden en la conformación de las organizaciones dada su naturaleza jurídica, corresponden al derecho mercantil, derecho civil, constitucional, administrativo y laboral. De tal forma se tiene que el derecho mercantil, el derecho empresarial y corporativo requieren forzosamente de un sistema de leyes que regule tanto las bases de la existencia de la empresa como la forma de constituirse, integrarse y disolverse cada uno de sus tipos legales, siendo aplicable lo relativo a la Ley general de sociedades mercantiles, Ley general de sociedades cooperativas, entre otras, de igual forma, la materia civil es supletoria del derecho mercantil, debido a que estudia la personalidad jurídica del ente moral. Se reconoce, en el artículo 25 fracción II, III, IV, V y VII del Código Civil Federal y su análogo, el artículo 25 del Código Civil del Distrito Federal, como persona jurídica-colectiva en general a las corporaciones de carácter público reconocidas por la ley, a las sociedades civiles o mercantiles, a los sindicatos y asociaciones profesionales, a las sociedades cooperativas y mutualistas, además de las personas morales extranjeras de naturaleza privada.

En relación con el derecho fiscal, desde el momento en que el empresario, para obtener la autorización del estado y poner en funcionamiento su empresa o negocio mercantil, debe cumplir con una serie de trámites que implican el pago de contribuciones económicas denominadas derechos, impuestos, etcétera, al fisco. Resulta importante puntualizar que para alcanzar el desarrollo socio-económico es indispensable que en el marco legislativo se introduzca la visión de desarrollo donde el crecimiento sea desde abajo, desde lo local a lo global, menos desigual y más equitativo. Los encargados de elaborar las leyes deben tener claro que no existe 
Año 10.

Frontera

Núm. 26
Revista de Investigación

Académica sin

ISSN: 2007-8870

\section{http://revistainvestigacionacademicasinfrontera.com}

una receta, que el desarrollo sólo podrá ser el resultado de la acción social organizada de los integrantes de las localidades. El desafío actual es muy complejo, y se requiere echar mano de todas las bondades del marco legislativo vigente para contribuir a desatar procesos locales de desarrollo y, desde estas mismas prácticas innovadoras sistematizar nuevos conocimientos que, a su vez, contribuyan de modo participativo en la generación de marcos legislativos más favorables para el crecimiento económico y el mejoramiento de la calidad de vida.

Si bien se han realizado reformas para simplificar la apertura de empresas, se requiere mayor efectividad, prontitud y certidumbre del sistema legal que de mayor eficacia en los contratos y mayor certidumbre de los derechos de propiedad. Es importante resaltar que se han emprendido importantes reformas para aumentar la rendición de cuentas y el profesionalismo del poder judicial, particularmente mediante la aplicación de los juicios orales, estos últimos en algunos estados son un proceso incipiente que requiere de mayor atención, capacitación y mejora en su implementación. (Herrera \& Gonzales, 2006)

\section{Conclusiones}

En la actualidad las empresas, enfrentan entornos diversos, complejos y globales, es común que las leyes suelen interpretarse como un conjunto de restricciones para el quehacer y operatividad de las organizaciones, según la perspectiva de este 
Año 10.

Frontera

Núm. 26
Revista de Investigación

Académica sin

ISSN: 2007-8870

\section{http://revistainvestigacionacademicasinfrontera.com}

análisis, el marco legal constituye el cauce de un proyecto para el desarrollo económico y social del país.

El Código de comercio, la Ley del impuesto sobre la renta, la Ley federal del trabajo y las demás leyes complementarias relacionadas con las empresas prestadoras de servicios o de productos, contienen las disposiciones necesarias para la creación de la empresa como un medio para el crecimiento económico y social del país. La empresa constituye un espacio de formación para aprender, mejorar las técnicas y los procesos en la elaboración de bienes y servicios convirtiéndose en uno de los principales motores activos del país. Bajo esta premisa, en esta investigación se abordó las principales leyes para el inicio y operación de las empresas, destacando que existen normas de conducta y reglamentos en cada interacción de personas. En las empresas, en particular, las reglas son fundamentales. Aunque muchas veces las normas empresariales son sobreentendidas, lo correcto es hacerlas explícitas, establecerlas y documentarlas.

Es importante concebir a la normatividad empresarial como el conjunto de reglas que determinan el funcionamiento de la empresa, regula el comportamiento del capital humano y da a conocer reglas explícitas para convivir en un ambiente de respeto y cordialidad para que las tareas de cada persona se puedan desarrollar de la mejor manera.

Las normas variarán y resulta importante considerar diferentes factores como son: el tipo de empresa, la actividad principal de la misma, el riesgo de los trabajadores, el capital humano, entre otros.

Es importante considerar que el marco normativo empresarial y en si las instituciones jurídicas resulta fundamental en el desarrollo económico de las naciones e incrementa las posibilidades de atraer inversión y alcanzar altas tasas 
Año 10.

Frontera

Núm. 26
Revista de Investigación

Académica sin

ISSN: 2007-8870

http://revistainvestigacionacademicasinfrontera.com

de desarrollo, el marco normativo debe dar certeza y actuar con eficacia con total apego al estado de derecho en consideración a que el crecimiento económico de un país depende entre otras cosas de su capacidad de proteger los derechos de los ciudadanos, hacer respetar los acuerdos y dar certeza a las realización de transacciones comerciales debe estar encaminado a proteger al empresario y a la propia empresa, a los trabajadores en general, deben favorecer un ambiente laboral justo, y por consiguiente la promoción y el desarrollo económico y social del país.

\section{Referencias}

Burgos. S.G. (2002). Derecho y desarrollo económico: de la teoría de la modernización a la nueva economía institucional. Revista de Economía Institucional, vol. 4, núm. 7, segundo semestre, 2002, pp. 174-199. Universidad Externado de Colombia. http://www.redalyc.org/pdf/419/41900710.pdf

Corona. C. (2012). Licenciatura en administración. Universidad Nacional Autónoma de México.

http://fcasua.contad.unam.mx/apuntes/interiores/docs/2012/administracion/3/1 344.pdf

Cámara de diputados del H. Congreso de la Unión (2017). Constitución Política de los Estados Unidos Mexicanos. www.diputados.gob.mx/LeyesBiblio/doc/1 240217.doc.

Hernández, S. (2006). Metodología de la investigación 4ta. Ed. Mc. Graw-Hill. México D.F. https://competenciashg.files.wordpress.com/2012/10/sampieri-etal-metodologia-de-la-investigacion-4ta-edicion-sampieri-2006 ocr.pdf. 


\section{Julio- Diciembre 2017}

Año 10.

Frontera

Núm. 26
Revista de Investigación

Académica sin

ISSN: 2007-8870

\section{http://revistainvestigacionacademicasinfrontera.com}

Herrera. T; Gonzales .B. (2006). El marco legislativo del Estado de Michoacán y el desarrollo local. Economía y Sociedad, vol. XII, núm. 19, enero-junio, 2007, pp. 45-69 Universidad Michoacana de San Nicolás de Hidalgo Morelia, México. http://www.redalyc.org/pdf/510/51001903.pdf.

Moreno. A. (2010). La responsabilidad social corporativa. Materiales de Responsabilidad Social Empresarial. Grupo de Investigación de Organizaciones Sostenibles. https://courses.edx.org/assetv1:OECx+B1156+1T2015+type@asset+block/Leccion2Introducci\%C3\%B3n RSE-V6.1.pdf.

Zaldívar. A. (2014). La suprema corte ante la transformación de México. http://www.nexos.com.mx/?p=22091 